Abteilung Bildgebende Diagnostik und Radio-Onkologie, Departement für Kleintiere, Vetsuisse-Fakultät Universität Zürich

Prof. Dr. med. vet. Barbara Kaser-Hotz

Arbeit unter Leitung von Janean Fidel BS, MS, DVM, Diplomate ACVIM (Medical

Oncology) \& ACVR (Radiation Oncology)

\title{
Reevaluation of the University of Wisconsin 2-Year Protocol for treating Canine Lymphosarcoma
}

\author{
Inaugural-Dissertation \\ zur Erlangung der Doktorwürde der \\ Vetsuisse-Fakultät Universität Zürich
}

vorgelegt von

E. Claire Inderbinen Kaiser

Tierärztin

von Zermatt, Schweiz

genehmigt auf Antrag von

Prof. Dr. med. vet. Barbara Kaser-Hotz, Referentin

PD Dr. med. vet. Franco Guscetti, Koreferent

Zürich 2006 


\title{
Reevaluation of the University of Wisconsin 2- Year Protocol for Treating Canine Lymphosarcoma
}

\begin{abstract}
This retrospective study investigated a population of 96 dogs with newly diagnosed malignant lymphosarcoma that were treated with the commonly used University of Wisconsin-Madison (UW-M) chemotherapy protocol. Pretreatment characteristics were analyzed to determine prognostic factors. Dogs with higher World Health Organization (WHO) stages (including stage IV) and dogs with hypercalcemia were at significantly higher risk of relapse $(P=0.018$, and $P=0.016$, respectively). Dose reduction, treatment delays and prior therapy with corticosteroids were not associated with clinical outcome. First remission duration of 270 days was similar to historically reported data. Overall survival time of 218 days was much shorter than historical data.
\end{abstract}

(This paper was written in the context of a doctoral thesis) 


\section{Introduction}

Lymphosarcoma, neoplasia arising from lymphoreticular cells, is one of the malignancies most likely to respond to chemotherapy, and it is also one of the most common neoplasms of the dog. ${ }^{1}$ Various chemotherapeutic regimens have been used and usually consist of multiple drugs. ${ }^{2,3}$ Response rates of 80 to $90 \%$ with median survival times of 250 to 300 days have been reported. ${ }^{2,4}$ Numerous studies have been undertaken to identify prognostic factors relating to response to treatment, length of remission, and survival times. Results from these studies have varied. ${ }^{5,6-11}$ One common treatment regime used for canine lymphosarcoma is the University of Wisconsin (UW)-Madison 2-year chemotherapy protocol. Studies with limited numbers of dogs have investigated survival times of dogs treated with this protocol. ${ }^{6,12,13}$

The objective of this retrospective study was to evaluate signalment, prognosis, and prognostic factors in a previously unreported canine population that underwent treatment with the UW-Madison chemotherapy protocol for lymphosarcoma.

\section{Materials and Methods}

\section{Case Selection}

Medical records were searched at the Small Animal Clinic, Veterinary School, University of Zurich from April 1996 to December 2002 for dogs with definitive cytologic or histopathologic diagnosis of lymphosarcoma, that had received no chemotherapy except corticosteroids before being treated with the UW-Madison 2- year chemotherapy protocol. Diagnosis of lymphosarcoma was made on the basis of cytologic examination of needle aspirates, and/or histologic examination of surgically excised lymph nodes or other tissue samples. If any question concerning the accuracy of a cytological diagnosis arose, histological examination of a tissue specimen was performed. 
Staging was done using the modified World Health Organization (WHO) staging system for canine lymphosarcoma and consisted of a complete blood count (CBC), a serum biochemistry profile, urinalysis, and thoracic radiography. ${ }^{2}$ Whenever the physical examination and/or the serum chemistry profile suggested visceral involvement, abdominal ultrasonography $(n=27)$ or radiography $(n=31)$ was performed. Leukemia was diagnosed based on bone marrow evaluation $(n=6)$ or cytologic examination of blood smears $(\mathrm{n}=11)$. The WHO staging system was modified as described in a previous study, so that extranodal lymphosarcomas were considered a separate stage. ${ }^{12}$ Stage VI was created based on the fact that extranodal lymphosarcomas do not clinically behave like stage $\mathrm{V}$ lymphosarcomas [Table 1].

The dogs were further divided into substage a (without constitutional signs), and substage $b$ (with clinical signs of illness). Factors that were investigated included age, gender, breed, weight, clinical stage and substage, anatomical location, presence of hypercalcemia (reference range $9.6-11.2 \mathrm{mg} / \mathrm{dl}$ ) or hyperbilirubinemia (reference range $0.145-0.44$ $\mathrm{mg} / \mathrm{dl}$ ), hematocrit, hemoglobin, presence of neurologic signs, prior treatments, time between onset of signs until first treatment, toxicities associated with chemotherapy, dose reductions and alterations in therapy, and therapy instituted at relapse. Month of presentation and month of relapse were also noted, in order to evaluate for seasonality, a factor anecdotally reported in dogs. Because absolute thrombocyte counts were not available in most cases (i.e., platelet numbers were indicated as sufficient, high or low), this parameter was not evaluated. Immunophenotyping was not routinely performed owing to cost concerns.

\section{Treatment Protocol}

The doses and frequency of drugs used in the UW-Madison protocol are shown in Table 2. In 22 dogs the first dose of vincristine ${ }^{\mathrm{b}}$ was reduced to $0.5 \mathrm{mg} / \mathrm{m}^{2}$ owing to concerns 
of increased toxicity in the first week of therapy when L-asparaginase and vincristine are combined. ${ }^{14,15}$

\section{Side Effects}

Toxicity was assessed based on the National Cancer Institute (NCI) toxicity grading system for hematological and gastrointestinal toxicities [Table 3]. Owners were questioned as to whether the dog had any signs of gastrointestinal toxicosis (e.g., anorexia, vomiting, or diarrhea) and whether the dog's demeanor had changed. In cases of myelosuppression (i.e., a neutrophil count $<3000 / \mu \mathrm{L}$ ), treatment was delayed for a week and subsequent doses of that drug were reduced. If severe drug-induced gastrointestinal toxicosis developed, therapy was withheld and the dosage of the agent thought to be the cause of toxicosis was reduced. Only treatment delays owing to toxicity were statistically evaluated.

\section{Responses and Outcomes}

Complete remission was defined as the disappearance of all clinical evidence of disease on physical examination, radiography, ultrasonography, $\mathrm{CBC}$ or biochemistries. A partial response was defined as a decrease in tumor volume $\geq 50 \%$, with no new lesions. Stable disease was defined as no change in tumor burden or $<50 \%$ decrease in tumor volume. Progressive disease was defined as appearance of new lesions and/or tumor growth.

The first remission duration was defined as the time between recognition of a complete remission until evidence of relapse. Overall survival time was defined as time from the first chemotherapy treatment until death from lymphosarcoma or treatment. Survival time was determined by review of the medical record or by contact with the referring veterinarian or owner. 
All dogs entering the study were included in analysis for overall survival time $(n=96)$. Dogs that received only one treatment and were euthanized or died were evaluated despite not completing the induction protocol. Only dogs that achieved remission were included in remission duration calculations $(n=76)$. Discrete factors evaluated for significance included gender, breed, clinical stage and substage, anatomical location, presence of hypercalcemia, presence of neurologic signs, prior treatments, toxicities experienced, dose reductions, alterations in therapy, and therapy at relapse. Continuous factors included age, body weight, hyperbilirubinemia, hematocrit, hemoglobin, and time between onset of disease until treatment, and toxicities experienced. Univariate analysis to assess the prognostic value of the different discrete cofactors was performed by the Kaplan-Meier method, together with the log rank or "Breslow" test. ${ }^{16}$ The associations between two discrete covariates were evaluated by Fisher's exact test using a computerized software program ${ }^{\mathrm{a}}$. In order to compare means of a continuous variable with respect to a factor with only two levels, the Mann-Whitney U-test was applied. ${ }^{16}$ For two continuous covariates, Peareson's correlation was computed with a $95 \%$ confidence interval. ${ }^{16}$ Month of presentation and month of relapse were evaluated by the goodness of fit Chi square-test. ${ }^{17}$ Variables that were identified to be significant in univariate analysis were included in a multivariate Cox proportional hazards model regression analysis with a forward and backward step selection, for both survival and remission. ${ }^{16}$ Results were considered to be significant with $P$ values $<0.05$.

Dogs were censored in analysis of remission duration if they were in remission at the end of the study, were lost to follow-up, or had died from other causes while in remission. Dogs were censored in analysis of survival if they were lost to follow-up, died from causes unrelated to lymphosarcoma or chemotherapy, or were alive at the end of the study period.

\section{Results}

Case Data 
Ninety-six dogs met the inclusion criteria for the study. The median age at diagnosis was 7.7 years (range $0.5-14$; mean $7.63 \pm 0.3$ years). Forty-six dogs were females (32 spayed) and 50 were males (18 castrated). The most common breeds included the Bernese mountain dog $(n=11)$, rottweiler $(n=5)$, German shepherd dog $(n=5)$, Doberman pinscher $(n=4)$, and Labrador retriever $(n=4)$. Forty seven dogs $(49 \%)$ were comprised of 30 additional breeds, and 20 animals were mixed breed dogs (21\%). The median weight was $31 \mathrm{~kg}$ (range 4 to $78 \mathrm{~kg}$; mean $30.0 \pm 1.5 \mathrm{~kg}$ ). Stage distribution is shown in Table 4 .

Seventeen dogs (18\%) were leukemic, 17 (18\%) had cranial mediastinal involvement, and six (6\%) had pulmonic involvement. The sites of involvement of the nine stage VI dogs were gastrointestinal $(n=3)$, ocular $(n=3)$, nasal $(n=1)$, and spinal $(n=2)$. Fifteen dogs $(16 \%)$ had hypercalcemia (median $14.8 \mathrm{mg} / \mathrm{dL}$, range 12.5 to $18.8 \mathrm{mg} / \mathrm{dL}$ ), eight of which had mediastinal involvement (stage I, mediastinum only [ $n=1]$, stage II [n=1], stage III [ $n=4]$, and stage IV [n=2]). Hypercalcemic dogs without mediastinal involvement were staged as stages III $(n=5)$, and IV $(n=2)$. Nine dogs had hyperbilirubinemia. The median bilirubin level of all dogs measured was $0.19 \mathrm{mg} / \mathrm{dL}$ (range 0.005 to $14.15 \mathrm{mg} / \mathrm{dL}$ ). The median hematocrit was $42.0 \pm 0.8 \%$ (range 18 to $61 \%$ ); the median hemoglobin was $14.4 \pm 0.3 \mathrm{~g} / \mathrm{dL}$ (range 3.8 to $21 \mathrm{~g} / \mathrm{dL})$. Three dogs were presented with neurologic signs. Correlations were found between WHO stage and age $(\mathrm{P}=0.0002)$, WHO stage and hypercalcemia $(\mathrm{P}=0.0227)$, as well as age and weight $(\mathrm{P}=0.021)$. Hypercalcemia was found in younger dogs in lower stages. Higher WHO stages were associated with greater age and smaller body weights. Fifty-four dogs received prior treatments that consisted of antibiotics $(n=24)$, corticosteriods $(n=14)$, antibiotics and corticosteroids $(n=11)$, or alternative medications, such as mistletoe or immunomodulatory drugs $(n=5)$. Median duration of pretreatment was $13.5 \pm$ 2.4 days (range 1 to 81 days). Median time from appearance of first clinical signs until treatment was $18 \pm 2.8$ days (range 4 to 165 days). The initial diagnoses were highest in the months of July $(n=10)$, August $(n=10)$, November $(n=15)$, and December $(n=10)$ but this 
pattern was not statistically significant $\left(\chi^{2}-\right.$ test $\left.=16.05 ; P=0.1393\right)$. A higher tendency of relapse was detected in the months of May $(n=8)$, June $(n=7)$, July $(n=7)$, and September $(\mathrm{n}=9)$, and October $(\mathrm{n}=7)\left(\chi^{2}-\right.$ test $\left.=15.75 ; P=0.1507\right)$. In the years from 1996 until the end of the study in 2004, not one dog relapsed in the month of April.

\section{Side Effects}

Side effects and dosage reductions are summarized in Tables 5 and 6. Side effects were most frequently experienced after the first week of treatment. The five dogs that died after their first treatment were all substage b in stage III $(n=2)$, stage IV $(n=2)$, and stage VI $(n=1)$. Twelve dogs suffered bone marrow toxicity after week 1 and 26 dogs had gastrointestinal toxicities; some dogs suffered concurrently from both. Sixteen dogs had to be hospitalized (mean duration $2.9 \pm 0.7$ days, range 1 to 11 days) for drug-induced toxicity. Six hospitalizations occurred after week 1 (6.2\%). Eleven dogs were hospitalized once; five dogs were hospitalized more than once (two or three times). The drug that most frequently caused side effects was vincristine ( 66 dogs). Thirteen dogs exhibited gastrointestinal toxicity after the first doxorubicin treatment in week 4 . In one case, vincristine-induced neuropathy was strongly suspected and vincristine was discontinued at week 15 of the protocol.

Treatment delays owing to toxicity usually occurred during the induction phase $(n=39)$. Remission duration was not significantly associated with dosage reductions ( $\mathrm{n}=43 ; P=0.248$ ) or treatment delays $(\mathrm{n}=35 ; P=0.233)$. Specifically for the 22 dogs that received vincristine at $0.5 \mathrm{mg} / \mathrm{m}^{2}$ in week 1 , there was no statistically significant influence on remission duration $(\mathrm{n}=19 ; P=0.10)$ and toxicities in week 1 for this group of dogs included gastrointestinal $(n=6,27 \%)$, bone marrow $(n=3,14 \%)$, hospitalizations $(n=2,9 \%)$, and death $(n=1,4 \%)$. 
Seventy-six dogs (79\%) experienced a complete remission. Dogs that did not achieve a complete response had various stages of disease, namely stage II $(n=1)$, stage III $(n=6)$, stage IV $(n=6)$, stage $V(n=4)$, and stage VI $(n=3)$. The median duration of the first remission was $270 \pm 20.3$ days. Breed and gender status had no statistical influence on remission. Univariate variables that significantly increased the likelihood of relapse were hypercalcemia $(P=0.017)$, and higher initial stage classification (stages IV, V and VI as opposed to stages I, II, and III; $P=0.018)$.

Of the 15 dogs that were hypercalcemic, 11 had a complete response. The median duration of the first remission for the 11 dogs was only $139 \pm 26.3$ days as opposed to $296 \pm$ 31.2 days for dogs that were normocalcemic. Hypercalcemia did not influence the likelihood of achieving remission. In univariate analysis the presence of leukemia resulted in shorter remission duration. Leukemic dogs had a median remission duration of $172 \pm 9$ days, as opposed to $296 \pm 30.5$ days for non-leukemic dogs $(P=0.02)$. There was a tendency for longer remission duration with dogs in substage a (308 \pm 43.7 days), versus substage $b(176 \pm$ 55.3 days), but substage alone was not statistically significant $(P=0.16)$. Being classified as substage a was not a significant predictor of the likelihood of remission $(P=0.21)$. The time period between onset of the disease and first chemotherapeutic administration was not associated with achievement or duration of remission $(P=0.90)$. Of the 19 dogs pretreated with corticosteroids, remission duration was not significantly impacted $(P=0.70)$.

Evaluation of multiple Cox regression by the backward search procedure revealed only two factors that remained statistically significant, namely elevated calcium $(P=0.037$; Figure 1), and higher WHO classification of stage $(P=0.016$; Figure 2$)$. Forward stepwise analysis revealed leukemia as a negative prognostic marker $(P=0.011)$, together with hypercalcemia $(P=0.007)$.

In 34 dogs a second remission was attempted with either the same protocol $(n=17)$ or with lomustine $^{\mathrm{h}}\left(60 \mathrm{mg} / \mathrm{m}^{2}\right.$ per os q 3 weeks, $\left.\mathrm{n}=17\right)$. A number of dogs received other rescue 
therapies, such as: mitoxantrone $(n=1)$, actinomycin $(n=1)$, alkeran $(n=1)$, or no treatment $(n=16)$ but were not included in the second remission analysis because of low numbers in each treatment group. Eighteen of 34 dogs (53\%) achieved a second remission, 11 of which received the same protocol and seven received lomustine. A significant difference in the length of second remission duration was detected between those treated with the same protocol and those treated with lomustine, with dogs reinduced with the same protocol having a significantly longer overall survival time than the latter group $(P=0.008$; Figure 3$)$.

\section{Outcomes}

Three dogs were still in remission at the end of the study $(845,1336$, and 1720 days after initial treatment). Eight dogs had died or were euthanized for causes unrelated to lymphosarcoma, with one dog experiencing each of the following: cardiomyopathy (week 3 of therapy), ophthalmic disease, gastric foreign body, neurological disease, renal failure, osteosarcoma, orthopedic disease, and sudden death after a dental procedure. Four dogs were lost to follow up at $329,456,806$, and 1333 days. The median survival time of all dogs was $218 \pm 15.90$ days. Univariate analysis identified WHO substage as a significant $(P=0.004)$ prognostic indicator of overall survival time. The median overall survival time for substage a was $443 \pm 136.1$ days; the median overall survival time for substage $b$ was $136 \pm 77.3$ days. Median overall survival time for dogs that achieved a complete remission was $322 \pm 68.6$ days.

\section{Discussion}

Many findings of this study were similar to previously published results. The median age and weight of the dogs was similar to other studies. ${ }^{12,13}$ The high number of intact females in this study may have been related to regional differences because in North American studies, intact females are typically underrepresented. ${ }^{9,14,18}$ In the present study 
clinical courses experienced by intact females were similar to spayed females and males. One new finding was the high percentage of Bernese mountain dogs, which might indicate a susceptibility to lymphosarcoma for this breed. A comparison of affected dogs with the overall hospital population was not performed however.

The current study identified hypercalcemia as a significant prognostic factor in univariate and multivariate analyses. This finding has been reported previously using univariate analysis in some studies, whereas other studies have reported no significance of hypercalcemia as a prognostic indicator., $92,14,19$ The study reported here further identified a negative correlation between hypercalcemia and age, and a positive association between hypercalcemia and lower WHO stages, a finding not previously reported. One European study found a WHO classification of stage IV to be a positive prognostic indicator for complete remission rates, whereas the present study identified stages IV, V and VI as negative prognostic indicators. $^{2}$

Dogs that received prednisone before starting the protocol were not at a disadvantage, which was similar to a former study. ${ }^{9}$ Other studies have reported that delays in therapy and dosage adjustments were most frequently associated with vincristine, a finding this study confirmed. ${ }^{14}$ Lowering the vincristine dose at week 1 did appear to decrease toxicity because only $14 \%$ of the dogs in this study experienced bone marrow toxicity versus $40 \%$ in a study by Northrup et al. ${ }^{15}$ Significant toxicity did occur in the present study in dogs given a reduced dose of vincristine in week 1 , at a level similar to previous reports on this protocol. This finding supported the contention that it is the combination of vincristine and L-aspariginase that causes bone marrow suppression more than the dose of vincristine alone. ${ }^{14,19}$ Evaluation of vincristine toxicity in week 1 of the present study was skewed however, in that certain dogs were selected to receive a reduced dose of vincristine at week 1 (often substage $\mathrm{b}$ or higher tumor burdens and considered to be at greater risk for toxicity). Avoiding toxicity at week 1 allowed subsequent administration of full dosages of vincristine for the remainder 
of the protocol (i.e., a permanent dose reduction was not made based on the dog having had a toxic reaction to the vincristine at week 1). Remission duration for dogs that received vincristine at $0.5 \mathrm{mg} / \mathrm{m}^{2}$ in week 1 was not shorter than the group that had the full dose, so it may be useful to consider a dose reduction in all dogs week 1, or at least in those that are considered to have the highest risk for side effects during initial induction.

The complete response rate of $79 \%$ was lower in this study than previously reported ( $84 \%$ to $87 \%$ ) using the same protocol. ${ }^{12,13}$ One European study also observed a similar $77 \%$ complete response rate. ${ }^{2}$ The median duration of the first remission was comparable to other studies. ${ }^{8,12-14}$ The overall survival was lower at 218 days than the previously reported 357 days. ${ }^{12}$ The lower survival may have been a real survival disadvantage or may have arisen from cultural differences, with European clients less likely to try multiple rescue protocols or choosing euthanasia sooner.

The current study contained several limitations, including a lack of control dogs; its retrospective nature; differences in diagnostic testing procedures, ancillary treatments, and methods of evaluation and follow-up. The large number of dogs in this study helped minimize some of these problems. Another important point was the possibility of some degree of backward stage migration, as low numbers of dogs placed in stages I to III $(n=43)$ had abdominal ultrasonography $(n=7)$ or radiography $(n=10)$ performed. As many as 26 dogs may have been staged lower than they actually were. When these 26 dogs were experimentally classified as stage IV-VI there was no longer a statistically significant difference between dogs in stages I to III $(\mathrm{n}=17)$ and dogs in stages IV to VI $(\mathrm{n}=79 ; P=0.32)$.

Additional factors may also have influenced treatment outcome in the dogs of this study. Immunophenotyping has been used to identify prognostic differences between the cellular subtypes of canine lymphosarcoma but was not performed in the study reported here. $^{21}$ 


\section{Conclusion}

Ninety-six dogs with lymphosarcoma treated with the UW-Madison 2-year chemotherapeutic protocol were reviewed. Hypercalcemia and higher stage of disease were confirmed as negative prognostic indicators independent of other variables. Treatment with corticosteroids prior to starting the chemotherapy protocol did not effect remission or survival. A correlation was found between young dogs, hypercalcemia and low-stage disease. A trend was seen for dogs being presented more often in winter (November and December) and summer (July and August). Dose reduction of vincristine in week 1 appeared to decrease toxicity without affecting remission length or survival and should be considered as a viable modification of the protocol particularly in dogs that are substage $b$.

\section{Footnotes}

${ }^{a}$ Statview version 5.0.1; SAS Institute Inc., Cary, NC 27513

${ }^{\mathrm{b}}$ Oncovi; Medika AG, Switzerland

${ }^{\mathrm{c}}$ Leunase; Farmamondo, Chiasso, Switzerland

${ }^{\mathrm{d}}$ Endoxan; Baxter AG, Switzerland

e Adriablastin RD; Pfizer AG, Zürich, Switzerland

${ }^{\mathrm{f}}$ Leukeran; GlaxoSmithKline, Muenchenbuchsee, Switzerland

${ }^{g}$ Methotrexat Proreo; Proreo Pharma AG, Liestal, Switzerland

${ }^{\text {h }}$ Prava; Bristol-Myers Squibb GmbH, Baar, Switzerland 


\section{References}

1. Vail DM, MacEwen EG, Young KM. Canine lymphoma and lymphoid leukemias. In: Withrow SJ, MacEwen EG, eds. Small Animal Clinical Oncology. $3^{\text {rd }}$ ed. Philadelphia: WB Saunders, 2001:558-590.

2. Teske E, van Heerde P, Rutteman GR, et al. Prognostic factors for treatment of malignant lymphoma in dogs. J Am Vet Med Assoc 1994;205:1722-1728.

3. Rassnick KM, Mauldin GE, Al-Sarraf R, et al. MOPP chemotherapy for treatment of resistant lymphoma in dogs a retrospective study of 117 cases (1989-2000). J Vet Intern Med 2002;16:576-580.

4. Rosenthal RC, MacEwen EG. Treatment of lymphoma in dogs. J Am Vet Med Assoc 1990;196:774-780.

5. Jagielski D, Lechowski R, Hoffmann-Jagielska M, et al. A retrospective study of the incidence and prognostic factors of multicentric lymphoma in dogs (1998-2000). J Vet Med A Physiol Pathol Clin Med 2002;49:419-424.

6. Kiupel M, Teske E, Bostock D. Prognostic factors for treated canine malignant lymphoma.Vet Pathol 1999;36:292-300.

7. Starrak GS, Berry CR, Page RL, et al. Correlation between thoracic radiographic changes and remission/survival duration in 270 dogs with lymphosarcoma. Vet Radiol Ultrasound 1997;38:411-418.

8. Greenlee PG, Filippa DA, Quimby FW, et al. Lymphomas in dogs. A morphologic, immunologic, and clinical study. Cancer 1990;66:480-490.

9. Baskin CR, Couto CG, Wittum TE. Factors influencing first remission and survival in 145 dogs with lymphoma: a retrospective study. J Am Anim Hosp Assoc 2000;36:404-409.

10. Dobson JM, Blackwood LB, McInnes EF, et al. Prognostic variables in canine multicentric lymphosarcoma. J Small Anim Pract 2001;42:377-384. 
11. Rosenberg MP, Matus RE, Patnaik AK. Prognostic factors in dogs with lymphoma and associated hypercalcemia. J Vet Intern Med 1991;5:268-271.

12. Keller ET, MacEwen EG, Rosenthal RC, et al. Evaluation of prognostic factors and sequential combination chemotherapy with doxorubicin for canine lymphoma. J Vet Intern Med 1993;7:289-295.

13. Vail DM, Kisseberth WC, Obradovich JE, et al. Assessment of potential doubling time (Tpot), argyrophilic nucleolar organizer regions (AgNOR), and proliferating cell nuclear antigen (PCNA) as predictors of therapy response in canine non-Hodgkin's lymphoma. Exp Hematol 1996;24:807-815.

14. Garrett LD, Thamm DH, Chun R, et al. Evaluation of a 6-month chemotherapy protocol with no maintenance therapy for dogs with lymphoma. J Vet Intern Med 2002;16:704-709.

15. Northrup NC, Rassnick KM, Snyder LA et al. Neutropenia associated with Vincristine and L-Asparaginase Induction Chemotherapy for canine Lymphoma. J Vet Intern Med $2002 ; 16: 570-575$.

16. Altman DG. Analysis of survival times. In: Practical Statistics for Medical Research. London: Chapman \& Hall/CRC, 1994:365-395.

17. Altman DG. Comparing groups - categorical data. In: Practical Statistics for Medical Research. London: Chapman \& Hall/CRC, 1994: 229-276.

18. Boyce KL, Kitchell BE. Treatment of canine lymphoma with COPLA/LVP. J Am Anim Hosp Assoc 2000;36:395-403.

19. Chun R, Garrett LD, Vail DM. Evaluation of a high-dose chemotherapy protocol with no maintenance therapy for dogs with lymphoma. J Vet Intern Med 2000;14:120-124.

20. Ponce F, Magnol JP, Ledieu D, et al. Prognostic significance of morphological subtypes in canine malignant lymphomas during chemotherapy. Vet J 2004;167:158166. 
Table 1

Modified World Health Organization Staging of Canine Lymphosarcoma

\begin{tabular}{ll}
\hline Stage & Organ Involvement \\
I a,b & Single lymph node \\
II a,b & Multiple lymph nodes on one side of diaphragm \\
III a,b & Generalized lymphadenopathy \\
IV a,b & Visceral organs \\
V a,b & Bone marrow, blood \\
VI a,b & Extranodal \\
\hline
\end{tabular}

${ }^{*}$ Substage $a=$ without clinical signs of disease, Substabe $b=$ with clinical signs of disease 


\section{Table 2}

University of Wisconsin 2- Year Chemotherapy Protocol for Canine Lymphosarcoma ${ }^{12}$

\begin{tabular}{|c|c|c|}
\hline Treatment Cycles & Drug & Dosage* \\
\hline \multicolumn{3}{|l|}{ Cycle 1 (Induction) } \\
\hline Week 1 & Vincristine & $0.7 \mathrm{mg} / \mathrm{m}^{2} \mathrm{IV}^{\dagger}$ \\
\hline Week 1 & L-Asparaginase & $400 \mathrm{IU} / \mathrm{kg} \mathrm{SC}$ \\
\hline Week 1 & Prednisone & $2 \mathrm{mg} / \mathrm{kg}$ PO \\
\hline Week 2,7 & Cyclophosphamide & $200 \mathrm{mg} / \mathrm{m}^{2} \mathrm{IV} / \mathrm{PO}$ \\
\hline Week 2 & Prednisone & $1.5 \mathrm{mg} / \mathrm{kg} \mathrm{PO}$ \\
\hline Week $3,6,8$ & Vincristine & $0.7 \mathrm{mg} / \mathrm{m}^{2} \mathrm{IV}$ \\
\hline Week 3 & Prednisone & $1.0 \mathrm{mg} / \mathrm{kg} \mathrm{PO}$ \\
\hline Week 4,9 & Doxorubicin & $30 \mathrm{mg} / \mathrm{m}^{2} \mathrm{IV}^{\ddagger}$ \\
\hline Week 4 & Prednisone & $0.5 \mathrm{mg} / \mathrm{kg} \mathrm{PO}$ \\
\hline \multicolumn{3}{|l|}{ Cycle 2 (Maintenance) } \\
\hline Week $11,15,19,23$ & Vincristine & $0.7 \mathrm{mg} / \mathrm{m}^{2} \mathrm{IV}$ \\
\hline Week 13, 21 & Chlorambucil & $1.4 \mathrm{mg} / \mathrm{kg}$ PO \\
\hline Week 17 & Methotrexate & $0.8 \mathrm{mg} / \mathrm{kg} \mathrm{IV}$ \\
\hline Week 25 & Doxorubicin & $30 \mathrm{mg} / \mathrm{m}^{2} \mathrm{IV}^{\ddagger}$ \\
\hline \multicolumn{3}{|l|}{ Cycle 3 (Maintenance) } \\
\hline Week $28,34,40,46,52,58$ & Vincristine & $0.7 \mathrm{mg} / \mathrm{m}^{2} \mathrm{IV}$ \\
\hline Week 31, 43, 55 & Chlorambucil & $1.4 \mathrm{mg} / \mathrm{kg}$ PO \\
\hline Week 37, 61 & Methotrexate & $0.8 \mathrm{mg} / \mathrm{kg} \mathrm{IV}$ \\
\hline Week 49 & Doxorubicin & $30 \mathrm{mg} / \mathrm{m}^{2} \mathrm{IV}^{\dagger}$ \\
\hline
\end{tabular}


Cycle 4 (Maintenance)

Week $65,73,81,89,97,105,121 \quad$ Vincristine

$0.7 \mathrm{mg} / \mathrm{m}^{2} \mathrm{IV}$

Week 69, 85, 101, 117

Chlorambucil

$1.4 \mathrm{mg} / \mathrm{kg}$ PO

Week 77, 93, 109

Methotrexate

$0.8 \mathrm{mg} / \mathrm{kg} \mathrm{IV}$

*IV=Intravenous; $\mathrm{SC}=$ Subcutaneous; $\mathrm{PO}=$ Orally

${ }^{\dagger}$ Initiated therapy at $0.5 \mathrm{mg} / \mathrm{m}^{2}$ if dog had a large tumor burden or was clinically ill.

DDelivered in $0.9 \%$ saline solution over 1 hour; $1 \mathrm{mg} / \mathrm{kg}$ dose for $\operatorname{dogs}<10 \mathrm{~kg}$. 


\section{Table 3}

National Cancer Institute Toxicity Scoring Scheme for Chemotherapy Related Side Effects

\section{Type of Toxicity}

Bone marrow

Gastrointestinal

Nausea, anorexia

Vomiting 1 to 5 times per day

Diarrhea 5 to 7 times per day

$<5 \%$ weight loss

Vomiting 6 to 10 times per day

Diarrhea $>7$ times per day

5 to $10 \%$ weight loss

$>10 \%$ weight loss
G3

\section{Score $\dagger$}

H1

$\mathrm{H} 2$

H3

$\mathrm{H} 4$

G1

G2

G4

\footnotetext{
${ }^{*} \mathrm{WBC}=$ Peripheral white blood cells $/ \mu \mathrm{L} ; \mathrm{N}=$ Peripheral neutrophils $/ \mu \mathrm{L}$

${ }^{\dagger} \mathrm{H}=$ hematological; $\mathrm{G}=$ gastrointestinal
} 
Table 4

World Health Organization Stage and Substage Distribution

of 96 Dogs with Lymphosarcoma

\begin{tabular}{|c|c|c|c|}
\hline Stage & Substage & No. Dogs & Percentage (\%) \\
\hline \multirow[t]{2}{*}{ I } & $\mathrm{a}$ & 2 & 2.1 \\
\hline & $\mathrm{b}$ & 1 & 1 \\
\hline \multirow[t]{2}{*}{ II } & $\mathrm{a}$ & 3 & 3.1 \\
\hline & $\mathrm{b}$ & 1 & 1 \\
\hline \multirow[t]{2}{*}{ III } & $\mathrm{a}$ & 19 & 19.8 \\
\hline & $\mathrm{b}$ & 17 & 17.7 \\
\hline \multirow[t]{2}{*}{ IV } & $\mathrm{a}$ & 9 & 9.4 \\
\hline & $\mathrm{b}$ & 19 & 19.8 \\
\hline \multirow[t]{2}{*}{$\mathrm{V}$} & $\mathrm{a}$ & 7 & 7.3 \\
\hline & $\mathrm{b}$ & 9 & 9.4 \\
\hline \multirow[t]{2}{*}{ VI } & $\mathrm{a}$ & 1 & 1 \\
\hline & $\mathrm{b}$ & 8 & 8.4 \\
\hline
\end{tabular}


Table 5

Toxicities Experienced with the University of Wisconsin 2-Year

Chemotherapy Protocol for Canine Lymphosarcoma

$\begin{array}{lll}\text { Type of Toxicity* } & \text { No. Dogs } & \text { Percentages }(\%)\end{array}$

Bone marrow

$\mathrm{H}$

3

3.1

$\mathrm{H} 2$

2

2.1

H3

3

3.1

$\mathrm{H} 4$

6

6.3

\section{Gastrointestinal}

G1

8

8.3

G2

27

28.1

G3

15

15.6

G4

3

3.1

\section{Other Toxicities}

Hair loss

13

13.5

Weight loss

0

0

Hemorrhagic cystitis

4

4.2

Cardiomyopathy

0

0

Death after Week 1

5

5.2

* See Table 3 for definition of toxicity scoring 
Table 6

Dose Reductions Following Toxicity from the University of Wisconsin 2-Year

Chemotherapy Protocol for Canine Lymphosarcoma

Drugs requiring Dosage Reductions $\quad$ No. Dogs $\quad$ Percentages $(\%)$

\begin{tabular}{lll}
\hline Methotrexate & 7 & 7.3 \\
Vincristine $<0.7 \mathrm{mg} / \mathrm{m}^{2 *}$ & 15 & 15.6 \\
Cyclophosphamide & 1 & 1 \\
Doxorubicin & 1 & 1 \\
Combined (vincristine, doxorubicin & & \\
and cyclophosphamide) & 1 & 1
\end{tabular}

${ }^{*}$ Excluding dogs reduced at Week one 


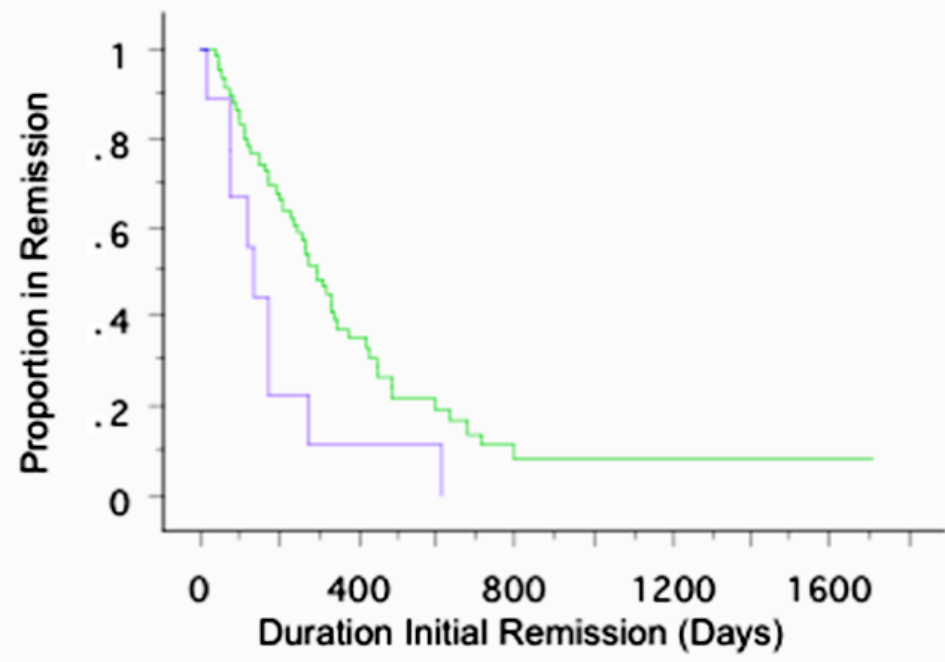

Normocalcemic dogs $(n=64)$

Hypercalcemic dogs $(n=11)$

Figure 1 - Kaplan-Meier median remission duration data comparing hypercalcemic and normocalcemic dogs with lymphoma that were treated with the University of Wisconsin 2-year chemotherapy protocol. Median remission durations were $139 \pm$ 20.3 days, and $296 \pm 31.2$ days respectively $(P=0.017)$. 


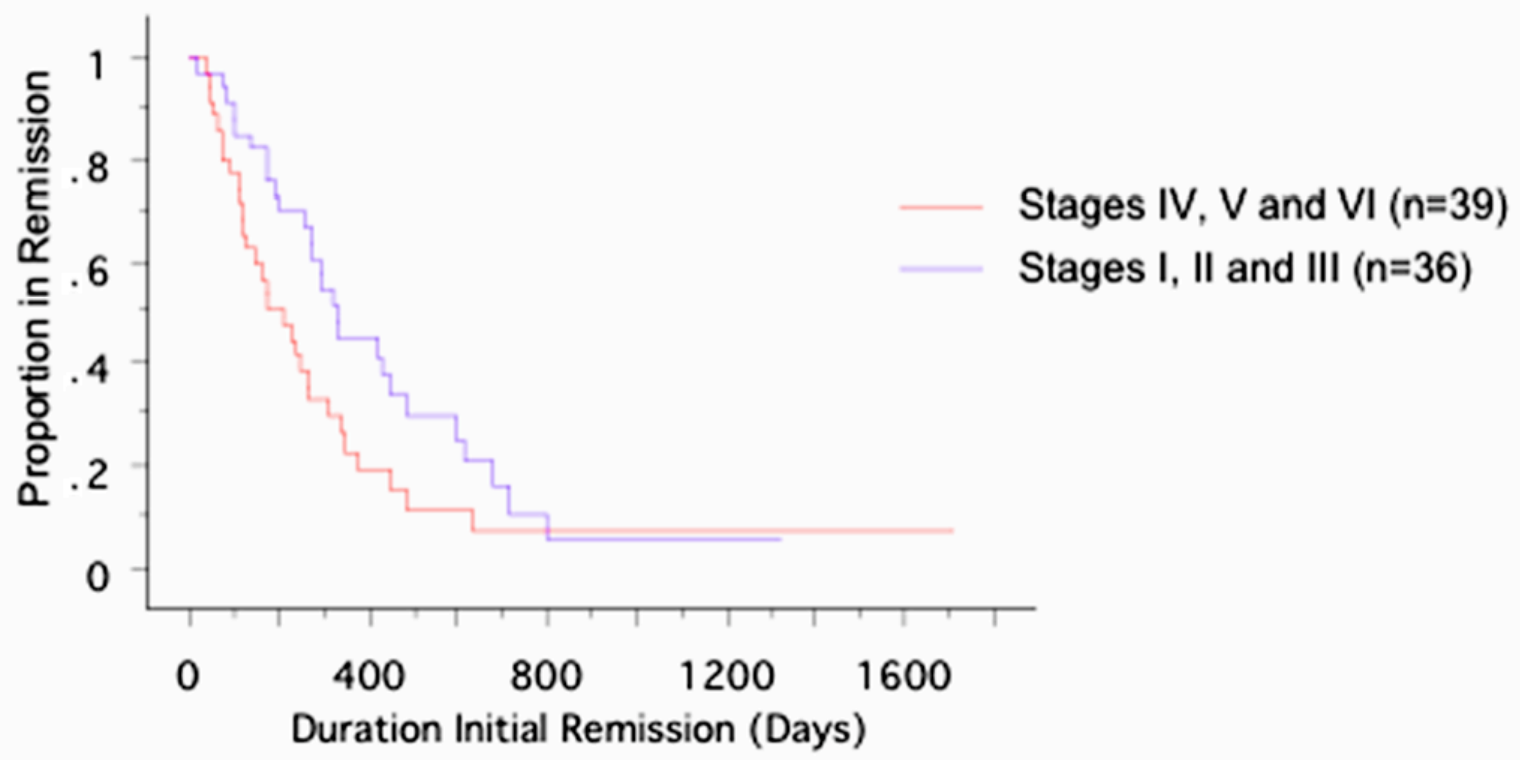

Figure 2 - Kaplan-Meier median remission duration data comparing dogs with lymphosarcoma classified as World Health Organization stages I-III and dogs classified as stages IV-VI. Median remission durations are $327 \pm 9.5$ days and $207 \pm$ 83.2 days respectively $(P=0.018)$. 


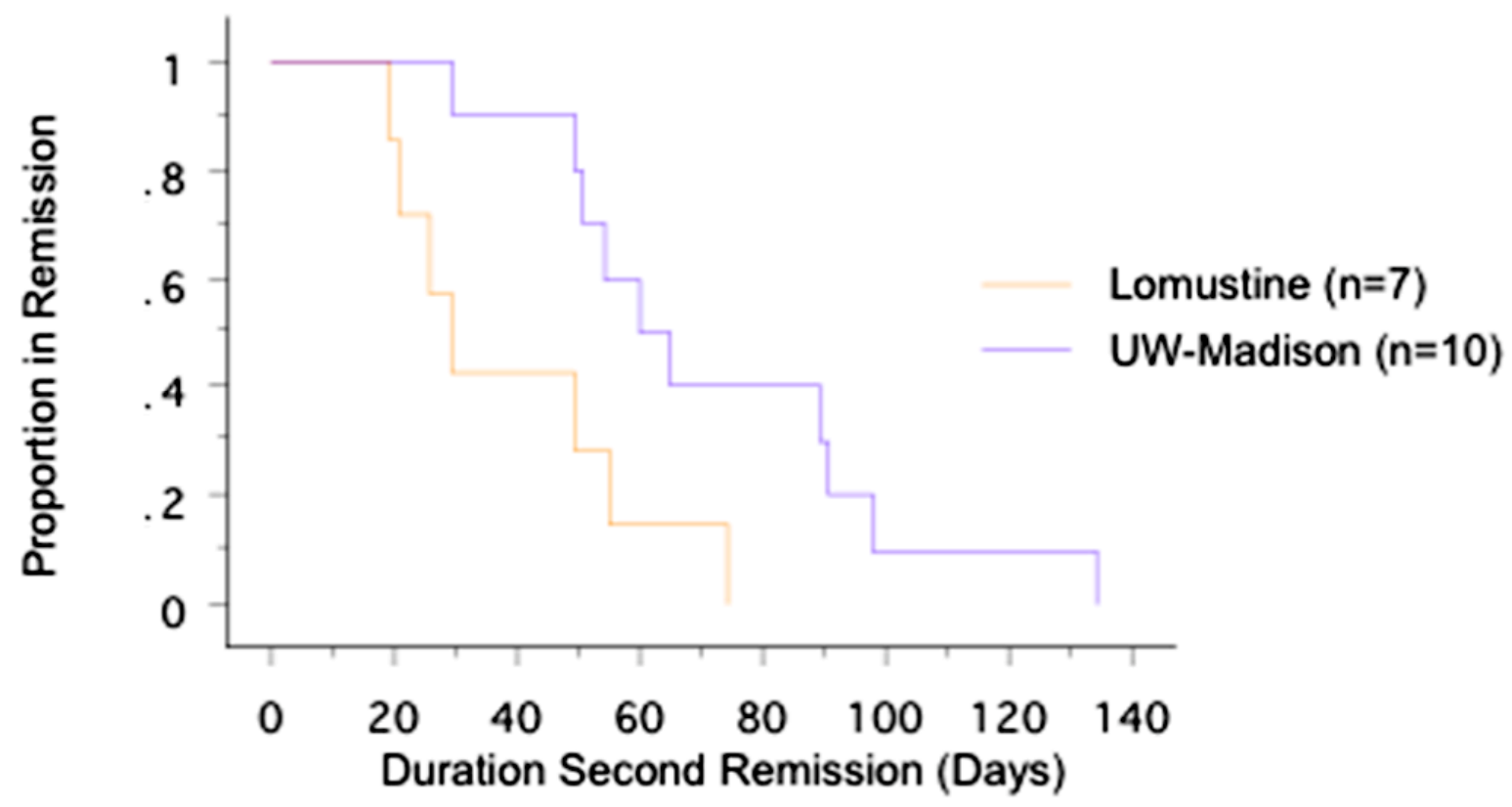

Figure 3 - Kaplan-Meier median second remission duration data comparing dogs treated with lomustine $\left(60 \mathrm{mg} / \mathrm{m}^{2}\right.$ per os q 3 weeks) with dogs treated with the University of Madison 2-year chemotherapy protocol at relapse. Median second remission durations were $29 \pm 15.1$ days and $60 \pm 8.7$ days respectively $(P=0.008)$. 


\section{Danksagung und Widmung}

An dieser Stelle möchte ich mich bei den vielen Menschen bedanken, ohne die diese Arbeit nicht zustande gekommen wäre:

- Herzlich danke ich Dr. Janean Fidel, die mich sowohl in Zürich wie auch an der Washington State University, Pullman USA, fachlich und menschlich unterstützt hat, für ihre stete Diskussionsbereitschaft und ihre Expertise.

- Frau Malgorzata Roos gilt mein Dank für ihre wertvollen statistischen Analysen und für das Einbringen von neuen, interessanten Anregungen und Gedanken.

- Mein ganz besonderer Dank gilt Frau Prof. Dr. med. vet. Barbara Kaser-Hotz, die es mir ermöglichte, diese Arbeit in Angriff zu nehmen, mir stets durch gute Betreuung zur Seite gestanden ist und den Fortschritt der Ergebnisse mit Interesse verfolgt hat.

- Ein grosses Dankeschön auch an Dr. med. vet. Cécile Rohrer Kaiser für ihre freundschaftliche Unterstützung und Hilfe zu Beginn dieser Arbeit.

- Herrn PD Dr. med. vet. Franco Guscetti danke ich für seine Bereitschaft, das Koreferat meiner Dissertation und die damit verbundenen Aufgaben zu übernehmen.

- Weiterhin möchte ich mich bei Dr. Dave Barbee für die Beschaffung der nötigen Software sowie bei Michel Dörrer und Christian Kaiser für ihren Support bei Anwenderproblemen bedanken.

- An meinen lieben Gatten Christian Kaiser und meine Familie richtet sich mein spezieller Dank; ohne ihre verständnis- und liebevolle Unterstützung wäre diese Arbeit nicht zustande gekommen.

Ich möchte diese Arbeit meinen Eltern widmen, die mir die Möglichkeit und die Freiheit gaben, meinen eigenen Berufsweg auszusuchen und zu verwirklichen. 